Atmos. Chem. Phys., 5, 2171-2180, 2005

www.atmos-chem-phys.org/acp/5/2171/

SRef-ID: $1680-7324 / \mathrm{acp} / 2005-5-2171$

European Geosciences Union

\title{
Large-scale validation of SCIAMACHY reflectance in the ultraviolet
}

\author{
G. van Soest, L. G. Tilstra, and P. Stammes \\ Royal Netherlands Meteorological Institute (KNMI), P.O. Box 201, 3730 AE De Bilt, The Netherlands
}

Received: 28 December 2004 - Published in Atmos. Chem. Phys. Discuss.: 21 March 2005

Revised: 30 June 2005 - Accepted: 3 August 2005 - Published: 12 August 2005

\begin{abstract}
In this paper we present an extensive validation of calibrated SCIAMACHY nadir reflectance in the UV (240$400 \mathrm{~nm}$ ) by comparison with spectra calculated with a fast radiative transfer model. We use operationally delivered nearreal-time level 1 data, processed with standard calibration tools. A total of 9 months of data has been analysed. This is the first reflectance validation study incorporating such a large amount of data. It is shown that this method is a valuable tool for spotting spatial and temporal anomalies. We conclude that SCIAMACHY reflectance data in this wavelength range are stable over the investigated period. In addition, we show an example of an anomaly in the data due to an error in the processing chain that could be detected by our comparison. This validation method could be extremely useful too for validation of other satellite spectrometers, such as OMI and GOME-2.
\end{abstract}

\section{Introduction}

The reflectance measured by a satellite instrument is at the basis of all geophysical information derived from the observations. The quality of the retrieved data depends crucially on the quality of the reflectance and its calibration. Besides, the spectral reflectance data set of the earth in the UV-visibleNIR range that was started with GOME (Global Ozone Monitoring Experiment) (Burrows et al., 1999) may be relevant for global change research, if it can be continued over a long time period. Therefore, it is of vital importance that the reflectance is carefully characterised spectrally and radiometrically, but also temporally and spatially to accommodate for trends and other systematic anomalies. Such a characterisation of SCIAMACHY nadir reflectance is the aim of this validation study. The properties of the observed radiation

Correspondence to: P. Stammes

(stammes@knmi.nl) as derived from the raw measurements are collectively called "level 1 data". These include earth radiance, solar irradiance, reflectance and polarisation.

Calibrated level 1 data is produced from the unprocessed (level 0) detector signal through application of a set of calibrations and corrections, e.g. wavelength calibration, radiometric calibration, polarisation correction, dark current corrections, etc. (Slijkhuis, 2001). Anomalies in level 1 data may be caused by the instrument, by the auxiliary parameters used for calibration and correction, and by the algorithms used to apply these.

A common strategy in the validation of retrieved geophysical parameters is the comparison with a collocated observation made by a different instrument. In the validation of level 1 data, this procedure is not generally applicable, as there is usually no instrument that can perform an independent collocated measurement. SCIAMACHY is in a relatively favourable position in this respect, since SCIAMACHY reflectance can be compared with that measured by MERIS (Medium Resolution Imaging Spectrometer) on the same platform (Acarreta and Stammes, 2005) and with the reflectance measured by the GOME spectrometer on ERS-2, which is in the same orbit with 30 min time difference. A drawback of this approach is the dependence on the calibration of the other instrument, which is a concern especially for the degraded UV channel of GOME. The MERIS calibration has been shown to be accurate to within 2-3\% (Santer et al., 2005), but this instrument is not equipped with a UV band. Validation of the SCIAMACHY IR channels is also not possible by comparing with these instruments.

The nadir reflectance measured by a satellite instrument can, however, also be validated by comparing it with the reflectance that is calculated with a radiative transfer model (RTM). In order for this method to work, a careful estimate has to be made of the state of the atmosphere that is being sampled, along with the sensitivity of the spectrum to all parameters. The estimated parameters are the input for the

(C) 2005 Author(s). This work is licensed under a Creative Commons License. 
RTM, which calculates the spectrum expected from the satellite instrument. We choose to employ this technique in this paper, and apply it to the UV part of the spectrum, for two reasons: first, it complements the validation by comparison with other satellite instruments, and second, the sensitivity of the UV spectrum to the ground albedo and clouds, which are the main uncertainties in the input parameters, is small, especially for $\lambda<350 \mathrm{~nm}$ (Tilstra et al., 2005). The major error source around $300 \mathrm{~nm}$ is ozone, which can be estimated accurately.

SCIAMACHY (Scanning Imaging Absorption Spectrometer for Atmospheric Chartography) is a large spectral range, medium resolution spectrometer aimed at studying the composition of the Earth's atmosphere (Bovensmann et al., 1999). The instrument was launched onboard the ESA Envisat platform in 2002. Several different retrieval algorithms are applied to obtain information about trace gas concentrations. The different methods present specific requirements to the quality of the level 1 data. Ozone, $\mathrm{NO}_{2}$ and other trace gas column densities, for example, are typically retrieved with a DOAS-type retrieval scheme (Platt, 1994), which is particularly sensitive to small scale spectral structure in the reflectance spectrum, and less so to broadband offsets. Ozone profile retrieval and retrieval of aerosol or surface properties, on the other hand, critically depend on the absolute radiometric calibration, and suffer less from spurious structures in the spectrum. Wavelength calibration is of crucial importance to all.

All systematic SCIAMACHY reflectance validation activities until present have concentrated on nadir data from specially processed verification data sets. Although these verification data have the same properties, in theory, as the operational data product, a validation of operational SCIAMACHY data may reveal characteristics of those data that would not be found otherwise. There may be accidental differences between the processing of dedicated verification data and the operational chain. More importantly, some systematic properties of the data only show up in a data set that covers a large area geographically and a long time span. Validation of a large data set may reveal certain correlations that are overlooked if single orbits are investigated. Conversely, due to considerations of computing time and data volume, investigation of a large data set is less suited for a high spectral resolution investigation of possible residual structure in the reflectance spectrum.

\section{Data and method}

\subsection{SCIAMACHY data}

We investigate SCIAMACHY data from the near-real-time delivery stream, dated from 1 September till 15 December 2003, and from 1 April till 31 August 2004. These data are commonly used as a basis for geophysical retrieval products generated by scientific institutes. Over these periods, the instrument was stable, apart from a decontamination between 18 and 30 June. Data from this period have been excluded from the study. There were no large changes in the operational level $0-1 \mathrm{~b}$ data processor configuration. The 2003 data have processor version 4.01 or 4.03 , while the 2004 data have versions 5.01 and 5.04. We found no trace of the change in minor version number in the data. Noticeable effects of the difference between the processor versions $4.0 x$ and 5.0x will be discussed below. Some parameters in the calibration key data have also changed, but signatures of a difference cannot be found in our analysis.

The level $1 \mathrm{~b}$ data are calibrated to level 1c using ESA's SciaL1C program, v2.2.9, using all calibration options (i.e., memory effect, dark current, stray light, pixel-to-pixel gain, etalon, and polarisation corrections, and wavelength and radiometric calibrations). From the calibrated radiance $I$ and solar irradiance $E$ observations, a reflectance $R_{\text {obs }}$ is calculated which is defined as:

$R_{\mathrm{obs}}=\frac{\pi I}{\mu_{0} E}$.

$\mu_{0}$ is the cosine of the solar zenith angle.

Each SCIAMACHY state is divided in four "substates", labelled "East", "East-Center", "West-Center", and "West", to yield four reflectance measurements per state. The dimensions of a substate are $240 \mathrm{~km}$ in the scan direction and $450 \mathrm{~km}$ in the flight direction of the satellite. Within each substate suitable ground pixels are averaged. The substates are introduced to limit data volume and computing time, and to average the very small signal for $\lambda<290 \mathrm{~nm}$, while keeping the possibility to study a possible viewing angle dependence and to be able to handle ground albedo variation. Four substates still allow a reasonably homogeneous ground albedo to be assigned to a scene and keep the possibility of investigating an eventual scan angle dependence.

\subsection{Simulation and data selection criteria}

The reflectance observed by SCIAMACHY is compared to the reflectance spectrum calculated with a radiative transfer model (RTM). The RTM we use is LidortA (van Oss and Spurr, 2002). This is a fast code based on the discrete ordinates algorithm (Chandrasekhar, 1950). In retrieval applications it has the enormous advantage of calculating the derivatives of the reflectance with respect to the input parameters analytically. We used this feature for determining the sensitivity of our method to some of the input parameters in another study (Tilstra et al., 2004). LidortA is a scalar model; the error made by ignoring the polarisation in the TOA (topof-atmosphere) reflectance is corrected using a precalculated look-up table. The RTM is run on the ECMWF pressure grid of 60 layers up to $65 \mathrm{~km}$. 
We calculate the relative difference $d_{\mathrm{R}}$ between the reflectance derived from data measured by SCIAMACHY and the reflectance $R_{\text {sim }}$ modelled by our RTM:

$d_{\mathrm{R}}=\frac{R_{\mathrm{obs}}}{R_{\mathrm{sim}}}-1$.

The wavelength range covered is $250-400 \mathrm{~nm}$ for most of the data studied, part of the comparison was only done for 270 $340 \mathrm{~nm}$ for reasons of computational cost. We only apply this method in the UV because this spectral range can be modelled well with relatively coarse guesses for the atmospheric state and ground albedo.

The sensitivity of the simulation to input parameters, as well as an end-to-end error estimate of the use of RTM simulations as a validation method, are the subjects of another paper (Tilstra et al., 2005). For a full discussion we refer to that work. Its main conclusion is that the standard deviation of the error in the simulation due to input parameters is approximately $3 \%$ over the wavelength range $250-400 \mathrm{~nm}$, and up to $8 \%$ around $305 \mathrm{~nm}$ where the sensitivity to the ozone profile and column is largest. The sensitivity study of Tilstra et al. (2005) does not include clouds. Our cloud filtering procedure adds an offset between $0 \%$ and $2 \%$ to their error estimate for $\lambda>310 \mathrm{~nm}$, which is largest for the longer wavelengths in the study. In general, the error in the simulation is caused almost exclusively by errors in ozone for $\lambda<300 \mathrm{~nm}$, while for $\lambda>330 \mathrm{~nm}$, only errors in surface and lower-atmosphere parameters, such as clouds, aerosol, and ground albedo, contribute. In the intermediate wavelength range, all input parameters add significantly to the simulation error.

The wavelength grid for the RTM run has a spacing of $1 \mathrm{~nm}$. SCIAMACHY data are convolved with a Gaussian synthetic slit function of $1 \mathrm{~nm}$ width before interpolating to the RTM grid. The ozone absorption cross section used in the RTM calculations was also convolved with this function. Since the contribution of inelastic scattering is small, and the atmospheric scattering cross sections are essentially constant over the $1 \mathrm{~nm}$ wavelength bins, this is an adequate approximation.

Based on the sensitivities of the RTM reflectance to input parameters, we defined a few criteria to decide upon acceptance or rejection of a ground pixel. These are listed below:

- Clouds: We only include (nearly) cloud-free pixels. The radiance from clouded pixels depends too strongly on the assumed value of the cloud albedo to be useful in a study like this.

The cloud mask is based on cloud fractions from the cloud retrieval scheme FRESCO (Koelemeijer et al., 2001), available from the TEMIS project website $^{1}$. FRESCO is a very stable, reliable cloud retrieval

\footnotetext{
${ }^{1}$ Tropospheric Emission Monitoring Internet Service, http://www.temis.nl/
}

scheme that has been validated against several independent data sets. The main drawback is that it overestimates cloud fractions over areas with large ground albedo in the $\mathrm{O}_{2}$-A band, leading to rejection of e.g. states over desert.

We require the state to have a maximum of $20 \%$ cloud coverage; if the average cloud fraction in a state is larger it is entirely rejected. From the states with a cloud fraction less than $20 \%$, only pixels with a cloud fraction smaller than 5\% are included in the average over the substate. In this paper, the term "cloud free" means that a scene fulfils this criterion.

The error introduced by treating a pixel with a $5 \%$ cloud fraction as "cloud free" can be estimated by studying the correlation between $d_{\mathrm{R}}$ and cloud fraction. We find that the maximum error incurred is $5 \%$ of the reflectance for $\lambda \approx 380 \mathrm{~nm}$, assuming $5 \%$ cloud coverage of the substate. For $\lambda<300 \mathrm{~nm}$ there is no sensitivity to clouds. In the set of accepted substates, we have $2 \%$ cloud coverage on average. It gives rise to a positive error of about 0.02 in $d_{\mathrm{R}}$, smaller for shorter wavelengths. The effect can be compensated in principle by adjusting the ground albedo, but our study of the albedo sensitivity of the TOA radiance (Tilstra et al., 2005) demonstrates that this is not straightforward, as for most common surface types the sensitivity is wavelength dependent.

- Ground albedo: Ground albedos for individual cloud free ground pixels are obtained from the GOME LER (Lambertian Equivalent Reflectance) database (Koelemeijer et al., 2003) by spatial and temporal interpolation. Subsequently the albedos of accepted ground pixels in each substate are averaged. For each state, only one RTM run is performed; the atmospheric and surface parameters are identical for the 4 substates. For this reason, the ground albedo of a state has to be homogeneous. Substates with a ground albedo that differs from the average albedo of the state by more than $20 \%$ are excluded from the comparison.

- Solar zenith angle: Only nadir SCIAMACHY data with small to moderate solar zenith angles are included. The cloud and ozone data, that are inputs for the RTM, often suffer from reduced accuracy for large solar zenith angles. This diminishes their value as a reference. To prevent any influence on our study, we only include data with solar zenith angles smaller than $75^{\circ}$, corresponding to SCIAMACHY state IDs 4-7.

- Missing input: (Sub)states for which any of the input data are missing are rejected.

Other inputs needed for the RTM run are temperature, pressure, and ozone profiles. The temperature and geopotential height profiles are taken from ECMWF operational analyses. For the ozone profiles we use either the TOMS v8 


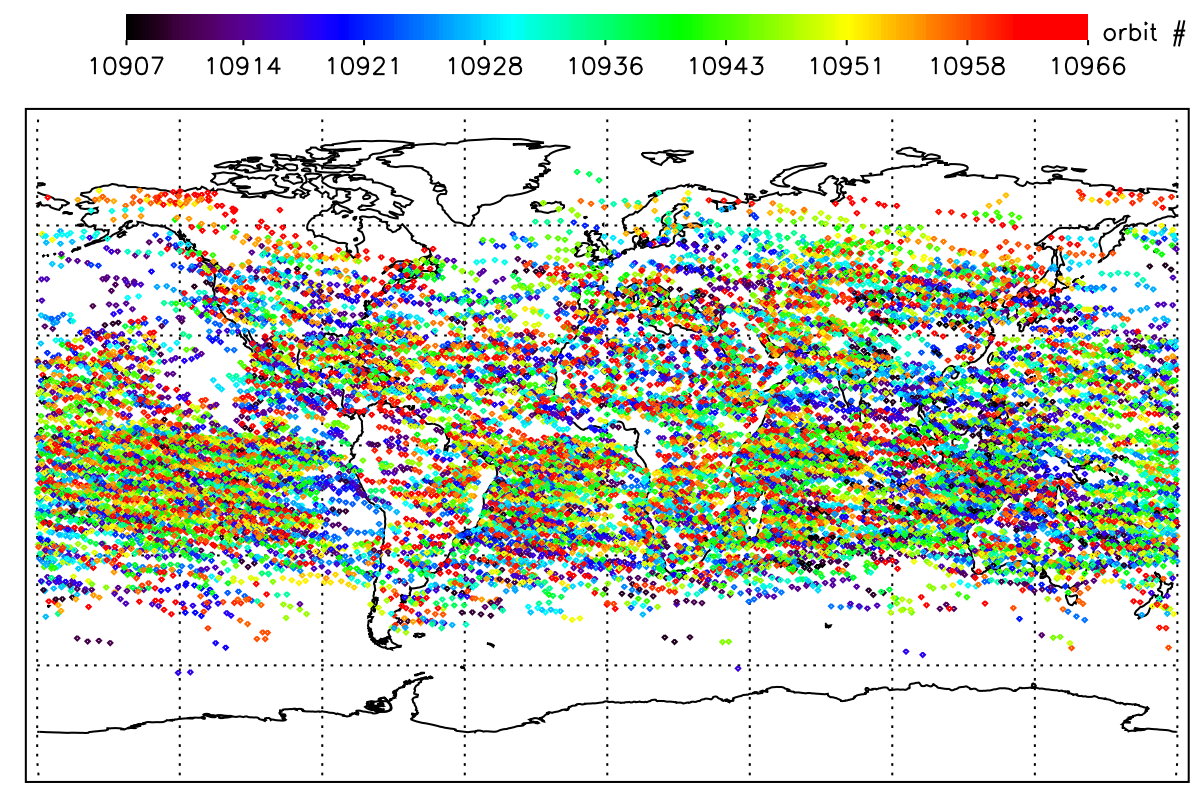

Fig. 1. Spatial distribution of all substates between April-June 2004 included in the study, using TOMS climatological ozone profiles for state selection. The colour codes the orbit number.

ozone profile climatology ${ }^{2}$ (McPeters et al., 2003), or profiles derived from collocated SCIAMACHY limb measurements in the Chappuis band (Rozanov et al., 2004; Brinksma et al., 2004). The TOMS climatology is parameterised in month, latitude, and ozone column. For the ozone column density we take an interpolated value from the assimilated TOSOMI data set (Eskes et al., 2004), available from the TEMIS website, and retrieved by a method that is not sensitive to absolute radiometric calibration. The ozone profiles are interpolated to ECMWF pressure levels, using ECMWF temperature and geopotential height profiles. We assume that no aerosol is present; a significant contribution to TOA radiance due to aerosol only occurs in desert areas and would give rise to an error in $d_{\mathrm{R}}$ smaller than $2-3 \%$ in those regions for $\lambda>300 \mathrm{~nm}$ (Tilstra et al., 2005). Desert areas are often (erroneously) flagged clouded by FRESCO and thus rejected.

The data included in the validation has a spatial coverage that is shown in Fig. 1. This figure represents all selected data from April till June 2004, using the TOMS climatology for ozone profiles. The coverage in the case of collocation with limb-retrieved ozone profiles is smaller as these are not always available.

Ideally, the relative difference between observation and simulation $d_{\mathrm{R}}=0$, though in practice we expect some scatter, caused by inaccuracies of the RTM input. Biases are either caused by the calibration of the measurement, or by systematic deviations of the input data. The probability of the latter has been minimised by the selection of the spectral range of

\footnotetext{
${ }^{2}$ available from the TOMS Version 8 website, http://toms.gsfc.nasa.gov/version8/version8_update.html
}

the study, where the sensitivity to most input parameters is small and by a very strict cloud mask. The only ingredient of the simulation that is difficult to filter is the ozone profile. A deviation in the ozone profile, however, gives a clear spectral signature and can thus be discriminated.

\section{Results and discussion}

In this section we will primarily discuss data from 1 April till 18 June 2004, using the TOMS climatology as an ozone profile source. Data from 1 July till 31 August 2004, using the TOMS climatology have also been studied, but for a smaller wavelength range. There is no difference between the two periods in 2004, before and after decontamination of the instrument.

\subsection{Spectral analysis}

Figure 2 shows a spectrum of histograms of relative differences between reflectances derived from measured SCIAMACHY data and calculated with the RTM. For each wavelength in the calculated spectrum, a histogram of relative differences is made. The bin size of the histograms is 0.02 . In Fig. 2 all data in accepted West (top) and East (bottom) substates from 1 April till 18 June 2004 are used (orbits $10907-$ 12036). Ozone profiles come from the TOMS climatology. The spectrum has been normalised to the absolute maximum count (100\% in the colour scale). The analysis of means and standard deviations was performed by fitting a Gaussian curve to the histogram for each wavelength. 

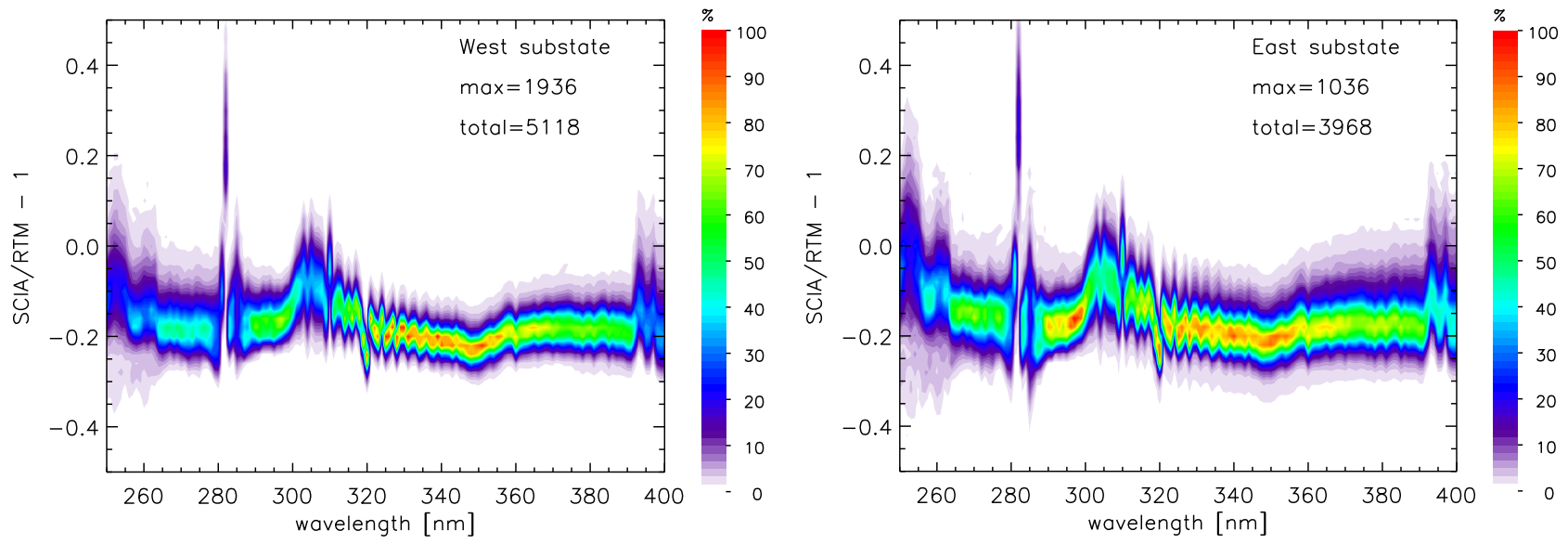

Fig. 2. Spectra of histograms of the relative difference between measured and calculated reflectances, normalised to the maximum value. (top) For West substates; (bottom) for East substates. In total, 3968 valid East substates are included, and 5118 valid West substates. The peak near $282 \mathrm{~nm}$ is a Fraunhofer line which has not been masked out in our analysis. The feature near $305 \mathrm{~nm}$ is due to the ozone profile used as input for the RTM.

A few observations can be made about Fig. 2. First, the relative difference over most of the spectral range is between -0.15 and -0.20 . This confirms previous findings in studies of the radiometric calibration of SCIAMACHY, compared to MERIS (Acarreta and Stammes, 2005) and GOME (Latter et al., 2003). The result is also consistent with a study comparing SCIAMACHY solar irradiance with theoretical reference spectra (Noël, 2004). The centre of the histograms for East substates is at a $d_{\mathrm{R}}$-value that is 0.01 higher than for West, in the range $310-400 \mathrm{~nm}$ (because the analysis is done by fitting, features of the ensemble that are smaller than the bin size can be discerned). This difference is smaller than the accuracy of the simulation applied to any one scene, but the standard deviation of the mean of an ensemble of scenes is smaller by $\sqrt{N}$. Since a difference between East and West substates persists in the average over thousands of scenes, it must be a real, systematic feature.

Second, there is a remaining feature between $300-310 \mathrm{~nm}$ which we attribute to a systematic inaccuracy of the ozone profile. We used the TOMS v8 Ozone Profile Climatology in these calculations, which has been developed for use with the TOMS instrument. Possible limitations in other applications have not yet been studied, to our knowledge. The feature in the spectrum would be broader $(300-320 \mathrm{~nm})$ if caused by a systematic deviation of the ozone column values used. In addition, validation of the TOSOMI algorithm has shown that the ozone column densities it yields underestimate the ozone column by approximately $2 \%$ compared to groundbased, rather than an overestimate which would be necessary to produce a smaller simulated reflectance.

Third, the spread in East substates for $\lambda>320 \mathrm{~nm}$ is larger than in West substates by about 0.02 . The standard deviation of $d_{\mathrm{R}}$ in West substates is between 0.025 and 0.05 , in East substates between 0.04 and 0.07 . We do not have a full explanation for this observation. The number of accepted substates is substantially smaller for East than for West. The larger rejection rate for East substates is probably due to sun glint geometries over ocean, which are detected as clouded by FRESCO. A residual effect of higher radiance caused by sun glint may persist in the comparison between observed and simulated reflectance, leading to a positive bias (1\% in Fig. 2) and smaller accuracy for East substates. In addition, the difference may be caused partly by shortcomings of the polarisation correction applied by the calibration utility, since East scenes are much more strongly polarised than West. However, the sensitivity of the instrument to polarisation between 320 and $340 \mathrm{~nm}$ is very small so there we expect no effect. Also, the polarisation sensitivity exhibits a spectral structure around $350 \mathrm{~nm}$, which we do not see in Fig. 2.

Fourth, an odd-even stagger is present, particularly for $300 \mathrm{~nm}<\lambda<340 \mathrm{~nm}$. This is probably an effect due to the undersampling of the ratio $d_{\mathrm{R}}$ and differences between the wavelength calibrations of the SCIAMACHY data and the ozone absorption cross sections we used. After we became aware of possible problems due to undersampling, we investigated the error incurred on a small set of spectra and found it to be less than $1 \%$ r.m.s. The effects of undersampling are only manifest on wavelength scales close to the grid spacing, and hence do not affect our conclusions which are about larger spectral ranges. However, in future applications of this method, it is advisable to decrease the sampling interval of the simulation to $0.5 \mathrm{~nm}$ at most, and interpolate these data to compute $d_{\mathrm{R}}$.

Finally, the spread for $\lambda<290 \mathrm{~nm}$ becomes larger for smaller wavelengths. This is due to the small signal in this wavelength range, and hence the extreme sensitivity to calibration accuracy. 


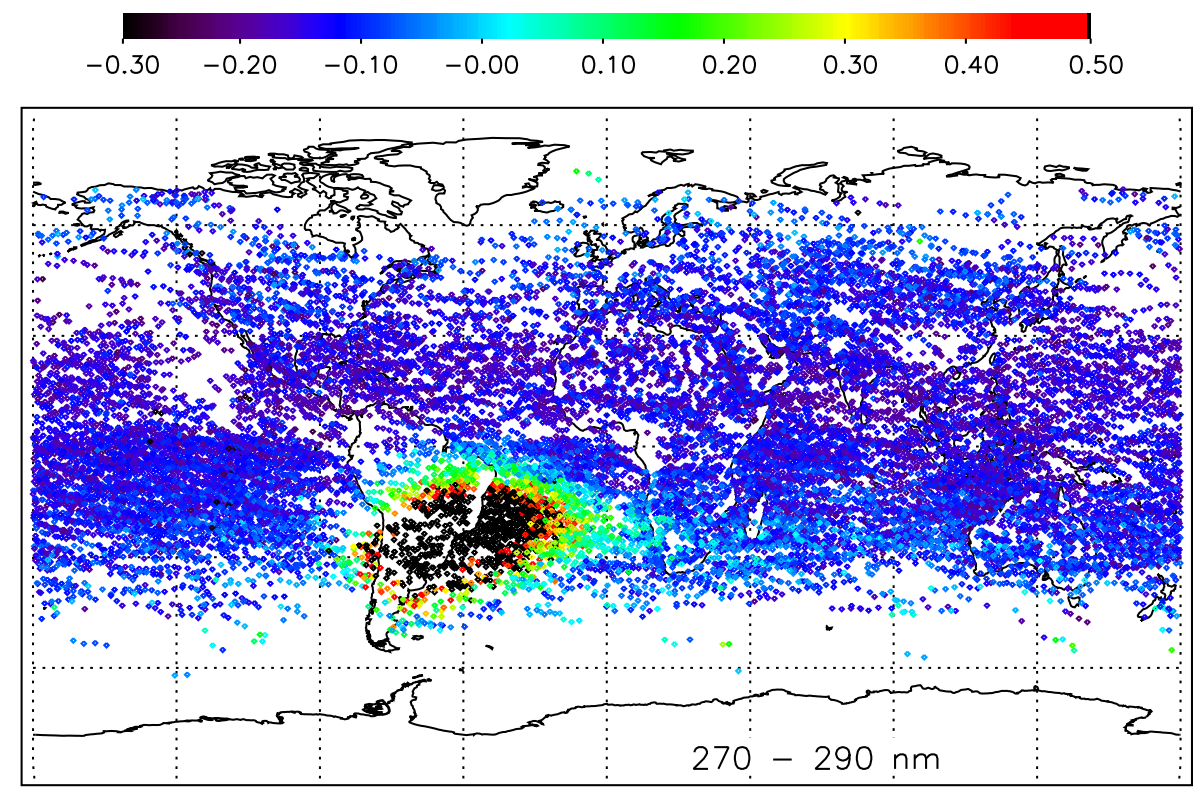

Fig. 3. Map of the relative difference between observed and simulated reflectance, $d_{\mathrm{R}}$, averaged between 270 and $290 \mathrm{~nm}$. The South Atlantic Anomaly is clearly visible.

The width of the $d_{\mathrm{R}}$-histograms shown in Fig. 2 (West) agrees well with the accuracy of the comparison predicted by the sensitivity studies presented by Tilstra et al. (2005). In the same study we found that for wavelengths larger than $400 \mathrm{~nm}$ the ground albedo has a large impact on the TOA radiance. The increasing spread in the relative difference $d_{\mathrm{R}}$ for $\lambda>320 \mathrm{~nm}$ is caused by the increasing sensitivity to ground albedo. Since the knowledge of surface albedo is limited, we do not apply this method to longer wavelengths.

We note that by this method, small scale spectral structure cannot be detected reliably. For this purpose, a careful comparison of individual spectra is a better strategy. However, it is possible to find anomalies of approximately $3-4 \mathrm{~nm}$ wide, provided the sensitivity to any of the input parameters does not exhibit any spectral structure at the wavelength under consideration.

One useful application of the results presented in Fig. 2 is the correction of the instrument's radiometric calibration with a polynomial fit based on the relative difference between observed and simulated reflectance. The advantages of determining a correction based on in-flight measurements are that it is based on the actual state of the instrument in operation, and it can easily be updated in a consistent manner to compensate for degradation effects.

\subsection{Geographical analysis}

The particular value of the technique we present in this paper is the potential to study spatial or temporal anomalies, which would not be found if a single state or a single orbit were studied. To demonstrate this, we made maps of the relative difference $\bar{d}_{\mathrm{R}}\left(\lambda_{0}\right)$, spectrally averaged in a $20 \mathrm{~nm}$ wide window around $\lambda_{0}$, given in nm. Figure 3 is a map of $\bar{d}_{\mathrm{R}}(280)$ (i.e. the mean $d_{\mathrm{R}}$ between 270 and $290 \mathrm{~nm}$ ), covering part of channel 1 of the instrument.

Figure 3 shows that $d_{\mathrm{R}}(280)$ is very constant over the globe, with values ranging between -0.20 and -0.10 , apart from the South Atlantic Anomaly (SAA), the large black spot over South America and the Southern Atlantic. There is no significant other geographical dependence. The magnitude of the increased noise in the SAA, caused by cosmic radiation, is large compared to the real detector signal, and thus appears as a large positive difference $R_{\mathrm{obs}}-R_{\mathrm{sim}}$. Our analysis clearly indicates the exact extent of the SAA, and provides a reliable data set that can be used to mask out the phenomenon. The current mask used in data processing is a rectangular box in (lon,lat) coordinates, extending from $\left(120^{\circ} \mathrm{W},-60^{\circ} \mathrm{S}\right)$ to $\left(50^{\circ} \mathrm{E}, 10^{\circ} \mathrm{N}\right)$. It covers all of Southern America, the Southern Atlantic, Central and Southern Africa and a large part of the Eastern Pacific (Slijkhuis, 2001). The masked region is so large that nearly half of the orbits pass through the SAA. Since calibration measurements that are flagged as being affected by the SAA are not used, an oversized mask leads to a waste of calibration data.

The scenes affected by the SAA have not been masked out in the analysis of Sect. 3.1. About one in 25 substates included in the analysis is in the SAA region, and these have a large, positive $d_{\mathrm{R}}$. Their contribution to Fig. 2 is a very sparse cloud of points with $\lambda<300 \mathrm{~nm}$ and positive $d_{\mathrm{R}}$. Its density is so low that it can not be seen in Fig. 2. The effect of scenes in the SAA on the discussion in Sect. 3.1 is very small, because the Gaussian fits to the histograms are 


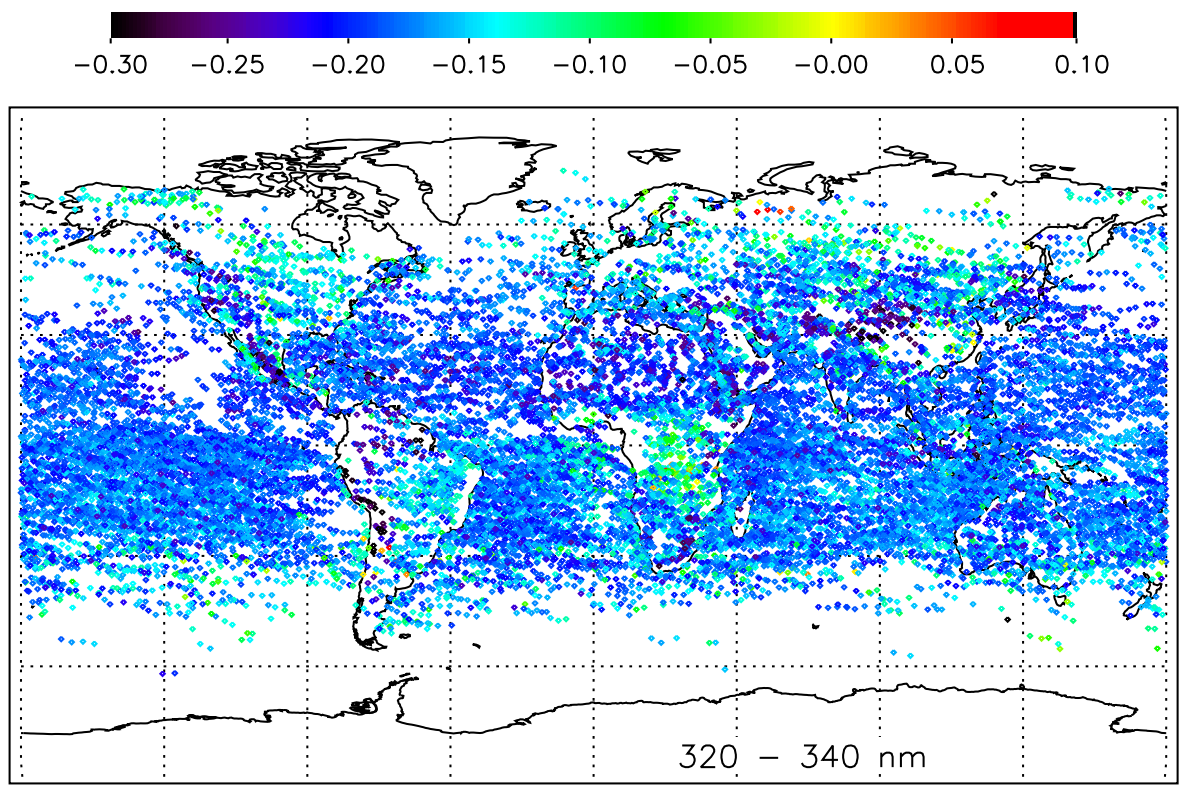

Fig. 4. Map of the relative difference between observed and simulated reflectance, $d_{\mathrm{R}}$, averaged between 320 and $340 \mathrm{~nm}$.

hardly affected by a sparse set of points in the far wing of the distribution.

In a similar manner as described for Fig. 3, we made a map of $\bar{d}_{\mathrm{R}}(330)$, displayed in Fig. 4. For this wavelength range, $320-340 \mathrm{~nm}$ in channel 2 of SCIAMACHY, $d_{\mathrm{R}}$ is again constant over the globe, with values scattered between -0.15 and -0.20 . Note that the colour scales for Figs. 3 and 4 differ. Only at higher northern latitudes, notably in Canada and Siberia, and in central Africa, $\bar{d}_{\mathrm{R}}(330)$ appears to be higher than for the rest of the world. We do not have an explanation for this observation. A possible cause for the higher observed reflectance in Africa could be an increased aerosol load due to biomass burning in this season, which we neglect.

Case study: Effect of erroneous dark current in 2003

The analysis of the data from 1 September-15 December 2003 was done with ozone profiles derived from SCIAMACHY limb measurements, in the wavelength range 270$340 \mathrm{~nm}$. This data set is more sparse because limb data are not available for all days, and because of a stricter setting (a maximum allowed difference of $10 \%$ ) of the filter for ground albedo inhomogeneity. The data show the same behaviour as discussed above for the channel 2 wavelength range 320$340 \mathrm{~nm}$, shown in Fig. 4. The relative difference between the reflectance observed by SCIAMACHY and that simulated by the RTM is homogeneous over the studied part of the globe, with values of $\bar{d}_{\mathrm{R}}(330)$ around -0.15 . On average, the relative difference in this data set is 0.03 less negative than the analysis of the 2004 data based on TOSOMI total ozone and TOMS climatology profiles. Whether this difference is caused by annual or seasonal effects in SCIAMACHY data, or by a difference in the ozone profiles used for the input of the simulation, cannot be decided strictly on the basis of these data. Ozone profile validation results (Brinksma et al., 2004), and the absence of observed seasonal effects in SCIAMACHY, however, suggest that the limb ozone profile is the most likely cause of the observed difference.

For the wavelength range in channel 1 , the conclusion is different. A map of $\bar{d}_{\mathrm{R}}(280)$ is shown in Fig. 5. Again, the SAA is clearly visible as a compact region of large observed radiance. However, there is another large region where the difference between SCIAMACHY and RTM reflectance is markedly higher than for the rest of the world, namely over the Central and Western Pacific, Australia, Eastern Asia, and the Indian Ocean. This area coincides with the region from which orbits are processed specifically by one of two Envisat data processing facilities, namely the ESRIN station. Four orbits daily are processed at ESRIN, the remaining ten are processed at Kiruna.

Investigation of the processor initialisation files showed that the ESRIN facility used an erroneous dark current file. The relative error in the tabulated parameter was negligible, but owing to the very small signal for wavelengths smaller than $300 \mathrm{~nm}$, the resulting error in the reflectance is $40 \%$. In other channels of SCIAMACHY, the calibrated detector signal is much larger and small errors in the dark current have a much smaller effect, that may often remain unnoticed.

As a result of a general processor reconfiguration, the faulty dark current file was replaced in March 2004. It is advised not to use SCIAMACHY channel 1 data processed by the ESRIN facility prior to this date. A difference between Kiruna and ESRIN orbits was also found in $\mathrm{SO}_{2}$ retrievals from channel 2 (A. Richter, personal communication, 


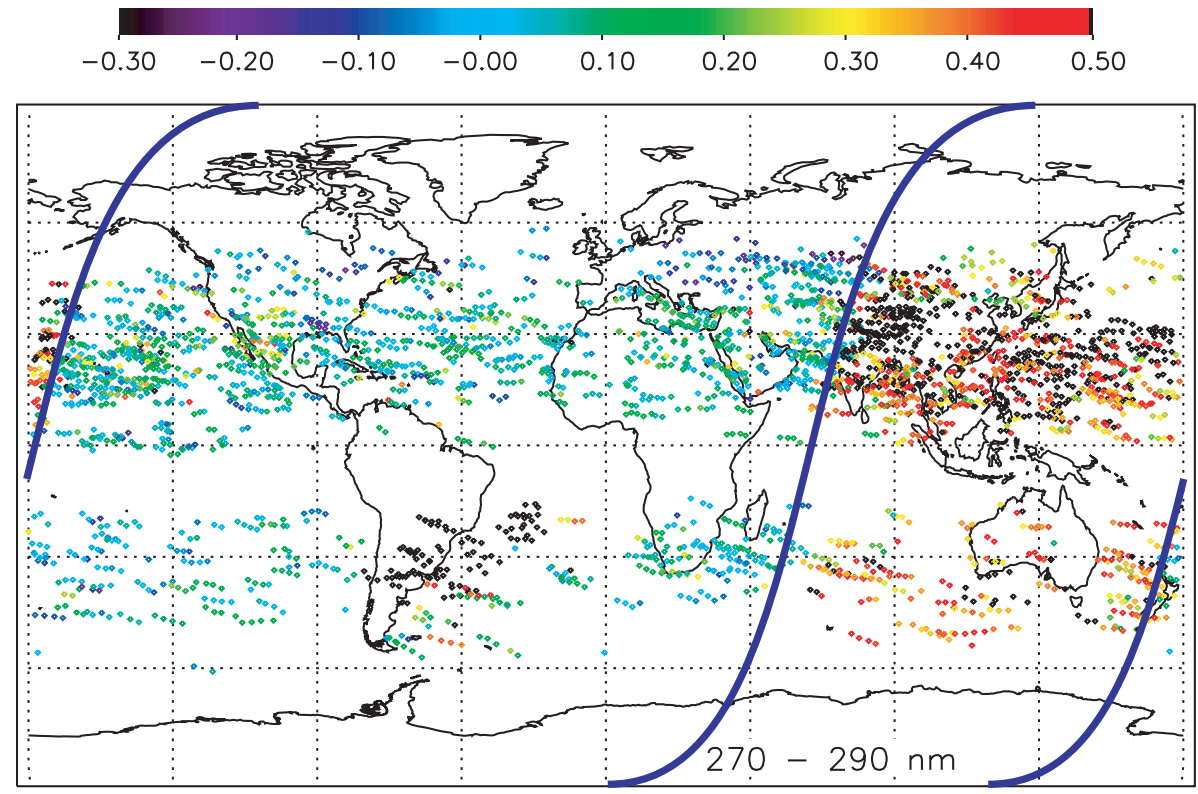

Fig. 5. As Fig. 3, for September-December 2003. The geographical area, from which the orbits processed at the ESRIN facility originate, is marked with blue lines. The SCIAMACHY data show a $40 \%$ offset in the reflectance in this region.

2004), probably caused by the same error. Investigation of TOSOMI ozone (retrieved from channel 2) and Observation minus Forecast data from the TOSOMI ozone assimilation showed no feature associated with the anomalies in level 1 data.

The average reflectance difference $\bar{d}_{\mathrm{R}}(280)$ of orbits processed at Kiruna is scattered between -0.10 and +0.10 . This higher average value compared to the 2004 data of Fig. 3 may be caused by the pointing inaccuracy of the Envisat platform, affecting the limb profiles (Brinksma et al., 2004). Pointing accuracy was improved in December 2003. The wrong altitude of the ozone maximum influences the integrated stratospheric ozone column density and hence the simulated spectrum.

\subsection{Temporal analysis}

A critical issue for long term instrument performance is degradation of optical components or sensors. Also, the calibration of the instrument may, for whatever reason, show slow drifts or seasonal variations that cannot be discovered by investigating a single state or orbit. Our validation system is a valuable tool for monitoring changes on long time scales.

An example is given in Fig. 6 . It displays the average $\bar{d}_{\mathrm{R}}$ over the entire wavelength range $(250-400 \mathrm{~nm})$, as a function of orbit number. Values $>0$ are in the SAA region and hence cannot be trusted. But the rest of the data present a clear picture. The instrument and its calibration are stable over the investigated period, except for two episodes (approx. orbits 11220-11280 and orbits 11950-12036) where the reflectance as derived from SCIAMACHY measurements is a significant 3\% lower than normal. After the first episode, the spread in the data starts to increase, until the end of the investigated period. The most probable explanation of these sudden changes of instrument behaviour is an operation or data processing change, though the documentation available to the authors does not mention any exceptions.

Case study: Decontamination in channel 1

With time, an ice layer forms on the infrared detectors of SCIAMACHY, because they act as a cold trap. This ice causes transmission loss and scattering problems. To alleviate this situation, SCIAMACHY is periodically heated to a temperature of $280 \mathrm{~K}$ to remove the ice layer. This heating is called decontamination. In these periods, data from the IR channels cannot be used, while the UV-Vis channels are supposedly not affected.

We performed our study for a period which included a decontamination episode. A non-nominal decontamination took place between orbits 12031 and 12 208. In channel 2 the effect of the heating is not significant, although the average reflectance observed by SCIAMACHY is about $1 \%$ lower than just before and after decontamination. But in channel 1 the effect of decontamination is huge, in fact, much larger than the effect of the SAA. The higher temperature increases the dark current by a relatively small amount, which is, however, about 10 times the calibrated signal for pixels in the wavelength range $270-290 \mathrm{~nm}$. This change in the dark current is not adequately accounted for. An example is given in Fig. 7. 


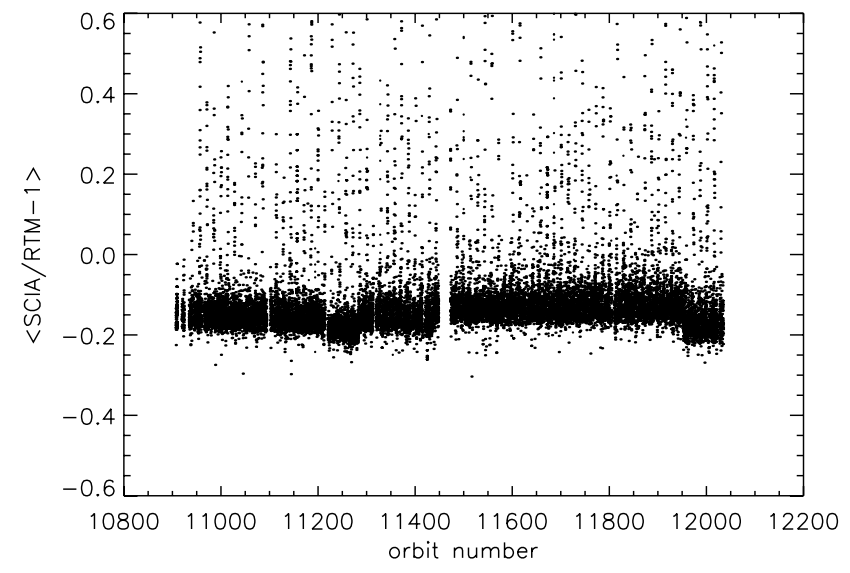

Fig. 6. Time series from 1 April-18 June 2004 of the average difference between observed and simulated reflectance for the entire wavelength range $250-400 \mathrm{~nm}$. Note the small, but striking, anomalies around orbit numbers 11250 and 12000 .

\subsection{Application to other instruments}

The validation of satellite-measured reflectance spectra by comparison with RTM simulations is not limited to SCIAMACHY. Other instruments for which this method may be successfully applied are OMI (Ozone Monitoring Instrument) and the GOME-2 series. In principle, it would also be suitable for GOME, but the stringent selection criteria for clouds and ground albedo homogeneity, given GOME's large ground pixel size, will lead to a high data rejection rate.

OMI (Stammes et al., 1999; Levelt et al., 2002) is ideally suited to be tested with the validation technique described in this paper. Most of the instrument's spectral range (270$500 \mathrm{~nm}$ ) can be simulated reliably. The small footprint ensures that many pixels are cloud free, and provide a good possibility to group pixels with a homogeneous ground albedo. Cloud retrieval from the $\mathrm{O}_{2}-\mathrm{O}_{2}$-band at $477 \mathrm{~nm}$ (Acarreta et al., 2004) can provide exactly collocated information for cloud masking. The range of viewing angles of OMI is very large, $114^{\circ}$, so it is important to be able to check viewing angle dependence. OMI has the advantage that it is not sensitive to polarisation. Our fast RTM provides the possibility to evaluate the large amount of data generated by the instrument.

GOME-2 is very similar to SCIAMACHY's UV-Vis channels in nadir mode. The comparison of GOME-2 reflectance with an RTM can be conducted in exactly the same manner as described here for SCIAMACHY.

\section{Summary and conclusions}

In this paper, we have presented a flexible and versatile method for validation of reflectance measured by remote sensing spectrometers in the UV. It was applied to SCIA-

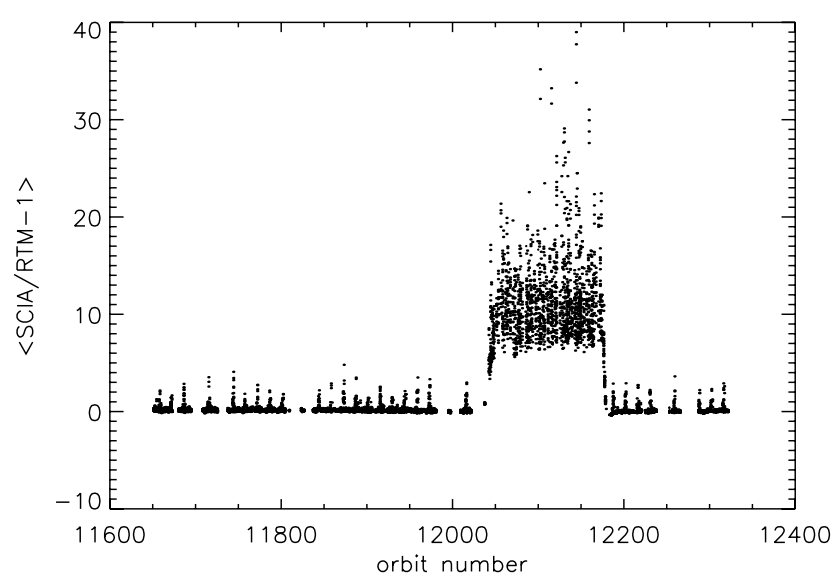

Fig. 7. Time series of $\overline{d_{\mathrm{R}}}(280)$ showing the effect of decontamination, between orbits 12031 and 12208 (18-30 June 2004), on channel $1 . d_{\mathrm{R}}$ rises to a value around $10(1000 \%)$ ! The usual assumption is that the UV-Vis channels of SCIAMACHY are not affected by decontaminations. The periodic small peaks rising to about 2 during the rest of the period are caused by states in the SAA.

MACHY level-1 data from the operational near-real-time data stream, that is often used by research groups as a basis for scientific retrievals. We have shown an analysis of data from late 2003 and mid 2004, demonstrating the power of the method.

The findings are consistent with earlier results, but supplements them in a number of ways. The spread in our histogram analysis of Fig. 2 validates the study of the reliability of the comparison between observed and simulated reflectance for single states (Tilstra et al., 2004, 2005). The extent of the SAA was shown to be much smaller than the mask that is currently used in data processing. Figure 3 can be used as a basis for a more accurate mask. The potential of our method for discovering inhomogeneities in the data processing or instrument performance were shown by the examples of the effect of decontamination on the reflectance in channel 1 (Fig. 7), and the large consequence of a small error in the dark current parameters used by the data processor (Fig. 5). We also found two short episodes where the reflectance (average $250-400 \mathrm{~nm}$ ) derived from the SCIAMACHY observations is approximately $3 \%$ lower than normal.

A general conclusion that we draw from all these examples is that observations for $\lambda<300 \mathrm{~nm}$ should be handled with care. The calibrated signal in this spectral range is orders of magnitude smaller than the corrections that are applied to the raw measurements. As a result, the level 1c data that are used as input for retrievals are extremely sensitive to calibration inaccuracies. The errors introduced can easily amount to $100 \%$. If these data are to be used for retrievals, an averaging procedure should be applied, as well as quality control, e.g. by comparing with an RTM. 
Acknowledgements. The work performed for this publication is (partly) financed by the Netherlands Agency for Aerospace Programmes (NIVR). Operational data processing and distribution are being performed by ESA and DLR-DFD within the Envisat ground segment.

We thank H. Eskes of KNMI for help with assessing the impact of reflectance anomalies on ozone retrieval. Ch. von Savigny of IFE/IUP at the University of Bremen is much acknowledged for making the limb ozone profile data set available to us. We are grateful to G. Lichtenberg at SRON and the SCIAMACHY Calibration Tiger Team for illuminating the calibration algorithms, and for stimulating discussion.

Edited by: U. Platt

\section{References}

Acarreta, J. R. and Stammes, P.: Calibration comparison between SCIAMACHY and MERIS on board Envisat, IEEE Geosci. Remote Sens. Lett., doi:10.1109/LGRS.2004.838348, 2005.

Acarreta J. R., de Haan, J. F., and Stammes, P.: Cloud pressure retrieval using the $\mathrm{O}_{2}-\mathrm{O}_{2}$ absorption band at $477 \mathrm{~nm}$, J. Geophys. Res., 109, D05204, doi:10.1029/2003JD003915, 2004.

Bovensmann, H., Burrows, J. P., Buchwitz, M., Frerick, J., Noël, S., Rozanov, V. V., Chance, K. V., and Goede, A. P. H.: SCIAMACHY: Mission objectives and measurement modes, J. Atmos. Sci., 56, 127-150, 1999.

Brinksma, E. J., Piters, A. J. M., Boyd, L. S., Parrish, A., Bracher, A., von Savigny, C., Bramstedt, K., Schmoltner, A.-M., Taha, G., Hilsenrath, E., Blumenstock, T., Kopp, G., Mikuteit, S., Fix, A., Meijer, Y. J., Swart, D. P. J., Bodeker, G. E., McDermid, I. S., and Leblanc, T.: SCIAMACHY ozone profile validation, Proceedings of the Second Workshop on the Atmospheric Chemistry Validation of Envisat (ACVE-2), ESA-ESRIN, Frascati, Italy, 37 May 2004, ESA SP-562, 2004.

Burrows, J. P., Weber, M., Buchwitz, M., Rozanov, V. V., Ladstätter-Weißenmayer, A., Richter, A., de Beek, R., Hoogen, R., Bramstedt, K., Eichmann, K.-U., Eisinger, M., and Perner, D.: The Global Ozone Monitoring Experiment (GOME): Mission concept and first scientific results, J. Atmos. Sci., 56, 151$175,1999$.

Chandrasekhar, S.: Radiative Transfer, Dover, New York, 1950.

Eskes, H. J., van der A, R. J., Brinksma, E. J., Veefkind, J. P., de Haan, J. F., and Valks, P. J. M.: Retrieval and assimilation of Sciamachy ozone columns, Proceedings of the XX Quadrennial Ozone Symposium (vol. I), Kos, Greece, 1-8 June 2004, 33-34, Athens, Greece, 2004.

Koelemeijer, R. B. A., de Haan, J. F., and Stammes, P.: A database of spectral surface reflectivity in the range $335-772 \mathrm{~nm}$ derived from 5.5 years of GOME observations, J. Geophys. Res., 108(D2), 4070, doi:10.1029/2002JD002429, 2003.

Koelemeijer, R. B. A., Stammes, P., Hovenier, J. W., and de Haan, J. F.: A fast method for retrieval of cloud parameters using oxygen A band measurements from the Global Ozone Monitoring Experiment, J. Geophys. Res., 106, 3475-3490, 2001.
Latter, B. G., Siddans, R., and Kerridge, B. J.: Intercomparison of reflectances observed by SCIAMACHY, GOME, AATSR and ATSR-2, Geophys. Res. Abstr., 5, 11 451, 2003.

Levelt, P. F., Veefkind, J. P., Voors, R. H. M., and de Vries, J.: OMI algorithm theoretical basis document: OMI instrument, level 01b processor, calibration \& operations, ATBD-OMI-01, vol. I, NASA, 2002.

McPeters, R. D., Logan, J. A., and Labow, G. J.: Ozone climatological profiles for version 8 TOMS and SBUV retrievals, Eos Trans. AGU, 84(46), Fall Meet. Suppl., Abstract A21D-0998, 2003.

Noël, S.: Determination of correction factors for SCIAMACHY radiances and irradiances, Tech. Note IFE-SCIA-SN20040514_IrrRadCorrection, Univ. of Bremen, Bremen, Germany, 2004.

Platt, U.: Differential Optical Absorption Spectroscopy (DOAS), in: Air monitoring by Spectroscopic Techniques, edited by: Sigrist, M. W., Chemical Analysis, 127, 27-76, New York, 1994.

Rozanov, A., von Savigny, C., Bovensmann, H., Bracher, A., and Burrows, J. P.: Description of the scia-arc SCIAMACHY scientific $\mathrm{O}_{3}$ and $\mathrm{NO}_{2}$ profile data set, http://www.iup.physik.uni-bremen.de/ $\sim$ sciaproc/STROZONE/ DOCU/Scia_data_doc.pdf, Univ. of Bremen, Bremen, Germany, 2004.

Santer, R., Martiny, N., and Smolskaia, I.: Vicarious calibration of MERIS over dark waters in the near infrared, accepted for publication in Proceedings of the Envisat Symposium, 6-10 September 2004, Salzburg, Austria, 2A2-106, 2005.

Slijkhuis, S.: Envisat-1 SCIAMACHY Level 0 to 1c Processing Algorithm Theoretical Basis Document, ENV-ATB-DLR-SCIA0041, Issue 2, Deutsches Zentrum für Luft- und Raumfahrt e.V., Oberpfaffenhofen, Germany, 2001.

Stammes, P., Levelt, P. F., de Vries, J., Visser, H., Kruizinga, B., Smorenburg, C., Leppelmeier, G., and Hilsenrath, E.: Scientific requirements and optical design of the Ozone Monitoring Instrument on EOS-CHEM, Proceedings of SPIE Conference on Earth Observing Systems IV, July 1999, Denver, Colorado, USA; SPIE Vol. 3750, 221-232, 1999.

Tilstra, L. G., Acarreta, J. R., Krijger, J. M., and Stammes, P.: Verification of SCIAMACHY's polarisation correction over the Sahara desert, Proceedings of Envisat Validation Workshop, Frascati, Italy, 9-13 December 2002, ESA SP-531, 2003.

Tilstra, L. G., van Soest, G., de Graaf, M., Acarreta, J. R., and Stammes, P.: Reflectance comparison between SCIAMACHY and a radiative transfer code in the UV, Proceedings of the Second Workshop on the Atmospheric Chemistry Validation of Envisat (ACVE-2), ESA-ESRIN, Frascati, Italy, 3-7 May 2004, ESA SP-562, 2004.

Tilstra, L. G., van Soest, G., and Stammes, P.: Method for in-flight satellite calibration in the ultraviolet using radiative transfer calculations, with application to SCIAMACHY, J. Geophys. Res. accepted, doi:10.1029/2005JD005853, 2005.

van Oss, R. F. and Spurr, R. J. D.: Fast and accurate 4 and 6 stream linearized discrete ordinate radiative transfer models for ozone profile retrieval, J. Quan. Spec., 75, 177-220, 2002. 